\title{
Effect of Supercritical Fluid Extraction on the Reduction of Toxic Elements in Fish Oil Compared with Other Extraction Methods
}

\author{
PARVANEH HAJEB, ${ }^{1 *}$ JINAP SELAMAT, ${ }^{1}$ LEILI AFSAH-HEJRI, ${ }^{1}$ NOR AINY MAHYUDIN, ${ }^{1}$ \\ SHAHRAM SHAKIBAZADEH, ${ }^{2}$ AND MOHD ZAIDUL ISLAM SARKER ${ }^{3}$ \\ ${ }^{1}$ Food Safety Research Centre (FOSREC), Faculty of Food Science and Technology, and ${ }^{2}$ Department of Aquaculture, Faculty of Agriculture, Universiti \\ Putra Malaysia, 43400 UPM, Serdang, Selangor, Malaysia; and ${ }^{3}$ Faculty of Pharmacy, International Islamic University Malaysia, Kuantan Campus,
} 25200 Kuantan, Pahang, Malaysia

MS 14-248: Received 30 May 2014/Accepted 22 July 2014

\begin{abstract}
High-quality fish oil for human consumption requires low levels of toxic elements. The aim of this study was to compare different oil extraction methods to identify the most efficient method for extracting fish oil of high quality with the least contamination. The methods used in this study were Soxhlet extraction, enzymatic extraction, wet reduction, and supercritical fluid extraction. The results showed that toxic elements in fish oil could be reduced using supercritical $\mathrm{CO}_{2}$ at a modest temperature $\left(60^{\circ} \mathrm{C}\right)$ and pressure $(35 \mathrm{MPa})$ with little reduction in the oil yield. There were significant reductions in mercury $(85$ to $100 \%$ ), cadmium (97 to 100\%), and lead (100\%) content of the fish oil extracted using the supercritical fluid extraction method. The fish oil extracted using conventional methods contained toxic elements at levels much higher than the accepted limits of $0.1 \mu \mathrm{g} / \mathrm{g}$.
\end{abstract}

Fish, with high-quality protein, vitamin D, selenium, omega-3 fatty acids, and other nutrients, is a major source of food for humans (2). Marine fish is rich in polyunsaturated fatty acids (PUFAs), particularly eicosapentaenoic acid (EPA) and docosahexaenoic acid (DHA). Intake of fish and fish oils is recommended to prevent cardiovascular diseases (5). The protective effects of fatty fish and fish oil supplements against coronary heart disease have been proven in several medical studies $(6,12,36)$. Fish oil supplements contain high doses of omega-3 PUFAs, which can decrease blood pressure in patients with hypertension and stabilize the mood in bipolar disorder, depression, attention-deficit hyperactivity disorder, and dementia $(9$, 27).

However, high levels of toxic elements may diminish the beneficial effects of fish and fish oil intake (13). Fish has been identified as the main source of toxic element (mercury, arsenic, cadmium, and lead) exposure in humans (4). Metals, such as mercury, arsenic, cadmium, and lead, are toxic elements that generally accumulate in fish tissues, such as muscle, liver, or offcuts. There have been several reports on toxic element contamination of fish and fish products from different regions of the world $(1,16,38)$. Any contaminated fish has the ability to transfer dangerous toxins to human through ingestion, and the risk of contamination is believed to increase as the quantity consumed increases. Recent studies showed high levels of

\footnotetext{
* Author for correspondence. Tel: +603-89423406; Fax: + 603-89423552; E-mail: parvaneh@upm.edu.my.
}

toxic elements in marine fishes from Malaysia $(1,15)$. Mackerel skin is extremely oily and contains a high level of PUFAs (29). Mackerel samples from Malaysia have also been reported to have high levels of mercury (15). In shortbodied mackerel, more than $70 \%$ of the mercury was in the form of organic mercury (14). In a survey of various fish oil supplements, Schmeisser et al. (32) reported that they contained from 4.3 to $10.5 \mu \mathrm{g} / \mathrm{g}$ total arsenic. Kołakowska et al. (21) reported $6.6 \mu \mathrm{g} / \mathrm{g}$ arsenic in cod liver and its oil. Lunde (22) reported $3.9 \mu \mathrm{g} / \mathrm{g}$ arsenic in the lipid extracts of cod liver and herring. The mercury concentration in different brands of fish oil studied by Foran et al. (8) ranged from 6 to $12 \mu \mathrm{g} /$ liter. In a previous survey of toxic element contamination in fish oils from Malaysia markets, mercury, arsenic, cadmium, and lead were detected (unpublished data). Therefore, there is a need to produce fish oil supplements with lower levels of contamination.

Supercritical fluid extraction (SFE) has been extensively used to remove metal ions from various solid and liquid matrices of environmental samples $(7,19)$. SFE has progressed recently as an effective extraction method in food industries, mostly due to the lower health and environmental hazards involved. This method is employed for the extraction and refinement of edible oils and fats, the extraction of animal fats, the removal of cholesterol from food and oils, decaffeination, and the extraction of hops and spices $(10,26)$. SFE successfully reduces the levels of other toxic chemicals, such as dioxins and polychlorinated biphenyls in fish oil $(17,23)$. However, this method has rarely been used for the detoxification of foods, particularly 
fish oils. One of the main goals of fish oil extraction is eliminating impurities without altering the nutritional compounds and the oxidative status of the oil (23). In this study, the efficiency of SFE in reducing the levels of toxic elements in fish oil compared with that of conventional extraction methods was evaluated.

\section{MATERIALS AND METHODS}

Chemicals and standards. Commercial liquefied $\mathrm{CO}_{2}$ (purity, 99.9\%), hydrogen (purity, 99.9\%), nitrogen (purity, 99.9\%), auxiliary gases, and compressed air (free from organic impurities) were purchased from Malaysian Oxygen Ltd. (Kuala Lumpur, Malaysia). Nitric acid (65\%), $n$-hexane, ethanol, petroleum ether, methanolic $\mathrm{NaOH}$, and methanolic borontrifluoride were obtained from Merck (Darmstadt, Germany). Sodium methoxide and bromelain $(6 \mathrm{U} / \mathrm{mg})$ were obtained from Sigma Aldrich (St. Louis, MO). The fatty acids standard mixture (37 Component FAME Mix) was purchased from Supelco (Milan, Italy). Toxic element standards (mercury, arsenic, cadmium, and lead) were obtained from Fluka (Tokyo, Japan).

Sample preparation. Samples of fresh short-bodied mackerel were collected from a fish market in Selangor, Malaysia. Different parts of the fish, including the skin, muscle tissue, and viscera were used for oil extraction. Samples were freeze-dried in a freeze dryer (Labconco, Kansas City, $\mathrm{MO}$ ) at $-47^{\circ} \mathrm{C}$ in a 0.133 bar vacuum. The dried samples were ground into particles, with sizes ranging from 0.2 to $0.5 \mathrm{~mm}$ by sieving. The moisture contents of the freeze-dried samples were determined following the AOAC International Official Method 934.01 (3).

Fish oil extraction methods. Four different methods were used for extracting oil from fish tissues. Triplicate samples prepared using each of the methods were analyzed. The percent oil yield was calculated using equation 1 , as follows:

$$
\text { Yield }(\%)=\frac{\text { Weight of the sample }(\mathrm{g})}{\text { Weight of the oil extracted }(\mathrm{g})} \times 100
$$

Solvent extraction (Soxhlet). A 10-g dried sample was extracted in triplicate using the Soxhlet method, with petroleum ether as the solvent, in a Büchi extraction system (model B-811, Essen, Germany). The extraction was conducted for $6 \mathrm{~h}$ in three extraction steps and then the solvent was evaporated using a rotary evaporator (Heidolph WB/VV 2000, Schwabach, Germany), and the samples were dried in an oven at $45^{\circ} \mathrm{C}$.

Wet reduction. A 50-g sample of homogenized fresh fish tissues mixed with $50 \mathrm{ml}$ of water was heated in a water bath at $95^{\circ} \mathrm{C}$ for $15 \mathrm{~min}$ and then centrifuged at $11,952 \times g$ at $20^{\circ} \mathrm{C}$ for $10 \mathrm{~min}$. The top layer containing the fish oil was collected and maintained at $-20^{\circ} \mathrm{C}$ prior to analysis.

Enzymatic extraction. Enzymatic extraction of fish oil was conducted following the method of Mbatia et al. (24). Fifty-gram samples of homogenized fresh fish tissues were mixed with $50 \mathrm{ml}$ of water. The mixtures were heated in a water bath to a temperature of $55^{\circ} \mathrm{C}$ for $15 \mathrm{~min}$ with stirring at $500 \mathrm{rpm}$, after which enzymatic hydrolysis was initiated by the addition of $0.5 \%$ bromelain (by wet weight of raw material). The contents were flushed with nitrogen, and hydrolysis proceeded for $2 \mathrm{~h}$. The hydrolysates were centrifuged at $11,952 \times g$ at room temperature for $15 \mathrm{~min}$. To recover the different fractions after centrifugation, the tubes were maintained upright at $-20^{\circ} \mathrm{C}$ for $2 \mathrm{~h}$, then the fractions were
TABLE 1. Operating condition for inductively coupled plasma mass spectrometry

\begin{tabular}{ll}
\hline \multicolumn{1}{c}{ Parameters } & Operating condition \\
\hline RF generator & $40 \mathrm{MHz}$ \\
RF power & $1,000 \mathrm{~W}$ \\
Nebulizer & Cross-flow \\
Nebulizer gas flow & 0.60 liter/min \\
Spray chamber & Ryton Scott \\
Plasma gas flow & 15.0 liters/min \\
Auxiliary gas flow & 1.0 liter/min \\
Sampler and skimmer cone & Nickel \\
Sweeps/reading & 20 \\
\hline
\end{tabular}

separated by cutting the frozen contents of the tubes, and the wet weights were determined.

SFE. The SFE of fish oil was conducted following the optimal conditions previously established in our laboratory (29). The SFE pilot unit used consisted- of an Intelligent HPLC pump (model PU-1580, Jasco Corporation, Tokyo, Japan) equipped with a cooling jacket to deliver $\mathrm{CO}_{2}$. Carbon dioxide from the supply tank was cooled using the cooling jacket attached to the pump. To cool the pump head, an ethylene glycol-deionized water mixture (50:50, vol/vol) circulated through the cooling jacket using a lowtemperature bath circulator (model 631D, Tech-Lab Manufacturing Sdn. Bhd., Selangor, Malaysia). A 10-g freeze-dried sample was placed in a 50-ml extraction vessel and heated using a column oven (model CO-1560, Jasco Corporation). The extraction occurred at a temperature of $60^{\circ} \mathrm{C}$ and a pressure of $35 \mathrm{MPa}$, using a flow rate of $2 \mathrm{ml} / \mathrm{min}$ for $6 \mathrm{~h}$. Under supercritical conditions, the oil dissolved in $\mathrm{CO}_{2}$ was separated in the back-pressure regulator (model BP1580-81, Jasco Corporation). The back-pressure regulator was used to reduce the pressure of the solvent and to separate the fish oil solute from the solvent in the trap. The fish oil separated from the supercritical phase using pressure reduction via an expansion valve was collected in the yield trap.

Toxic element analysis. Toxic elements were extracted in all of the samples following the method described by Hajeb et al. (14). One-gram samples of fish oil or fresh or freeze-dried fish tissues were weighed in digestion tubes, then $5 \mathrm{ml}$ of $\mathrm{HNO}_{3}(65 \%)$ was added, and the mixture was digested at 40 to $90^{\circ} \mathrm{C}$ for $3 \mathrm{~h}$. The digested samples were cooled and subsequently diluted to $40 \mathrm{ml}$ using deionized water. The elements in the filtered samples were analyzed using inductively coupled plasma mass spectrometry (ICP-MS; Perkin-Elmer, Waltham, MA). The analytical blank samples were evaluated in the same way as the experimental samples, and the concentrations were determined using standard solutions prepared in the same acid matrix. The operating condition for the analysis of toxic elements using inductively coupled plasma mass spectrometry is presented in Table 1.

The recovery of the elements was determined by spiking the samples with 5,10 , or $15 \mathrm{ng} / \mathrm{ml}$ of the standard solutions. The concentration of the elements in the resulting solutions were analyzed. The limit of detection and the limit of quantification of the four elements were determined by serial dilutions of the lowest calibrator concentration and established at a ratio of signal/noise of $>3$ and a ratio of signal/noise of $>10$. The recoveries, limit of detection, and limit of quantification for the four elements are shown in Table 2.

Fatty acid analyses. The fatty acid compositions of the fish oil extracted using each method were determined according to the 
TABLE 2. The recoveries, limits of detection, and limits of quantification of mercury, arsenic, cadmium, lead, and selenium

\begin{tabular}{lccc}
\hline Element & Recovery (\%) & $\begin{array}{c}\text { Limit of } \\
\text { detection }(\mathrm{ng} / \mathrm{g})\end{array}$ & $\begin{array}{c}\text { Limit of } \\
\text { quantification }(\mathrm{ng} / \mathrm{g})\end{array}$ \\
\hline Mercury & 97.7 & 0.001 & 0.003 \\
Arsenic & 95.1 & 0.001 & 0.003 \\
Cadmium & 102.0 & 0.0001 & 0.0003 \\
Lead & 93.5 & 0.0001 & 0.0003 \\
Selenium & 97.1 & 0.001 & 0.003 \\
\hline
\end{tabular}

method of Sahena et al. (30) and Khoddami et al. (18). An aliquot of fish oil sample was esterified using methanolic $\mathrm{NaOH}$ and methanolic borontrifluoride, and then the fatty acid methyl esters were extracted using hexane. The fatty acid methyl esters composition was determined using gas chromatography (model 4D, Shimadzu, Japan), with a flame ionization detector and an OmegaWax fused-silica capillary column (film thickness: $0.25 \mu \mathrm{m}$; 0.25-mm inside diameter; length: $30 \mathrm{~m}$; Supelco, Bellefonte, PA). The oven temperature was programmed to be $50^{\circ} \mathrm{C}$, which was held for $1 \mathrm{~min}$, and then increased to $220^{\circ} \mathrm{C}$ at $4{ }^{\circ} \mathrm{C} / \mathrm{min}$ and held for $25 \mathrm{~min}$. The injector and detector temperatures were set at $250^{\circ} \mathrm{C}$. The fatty acids were identified by comparing their retention times with those of the reference standard mixture.

Statistical analysis. The statistical analysis was conducted using an analysis of variance with significance set to $P<0.05$ to compare the differences between the extraction methods, using the Minitab version 13.2 statistical package (Minitab Inc., State College, PA). The variation between the elemental reduction achieved using the different methods and the different parts of the fish and the fatty acid contents of the extracted oils was evaluated using the Duncan $t$ test.

\section{RESULTS AND DISCUSSION}

Efficiency of the extraction methods. The moisture contents of the fresh samples of flesh, skin, and viscera used in the wet reduction and enzymatic extractions were $74.99 \%$ $\pm 0.03 \%, 72.95 \% \pm 0.36 \%$, and $76.63 \% \pm 0.36 \%$, respectively. The moisture contents of the freeze-dried samples of flesh, skin, and viscera extracted using the Soxhlet and SFE methods were $2.85 \% \pm 0.32 \%, 3.79 \% \pm$ $0.14 \%$, and $2.75 \% \pm 0.11 \%$, respectively. The total oil yields obtained using the different extraction methods are shown in Figure 1. SFE was a more efficient extraction method compared with the enzymatic extraction and wet reduction methods. The difference between the yields obtained using the Soxhlet and SFE methods were not significant $(P>0.05)$. The highest yield was obtained from fish skin, followed by the viscera and flesh using all four of the extraction methods. This result could be due to the moisture contents of the raw materials used. According to Rubio-Rodríguez et al. (28), the highest extraction yield is reached when the moisture content of the fish material is less than $20 \%$, as it was in the freeze-dried fish extracted using the SFE and Soxhlet methods. In wet reduction and enzymatic extraction, oil is extracted by denaturing or hydrolyzing the fish proteins by the action of heat or by an enzymatic reaction, followed by centrifugation. In this study, the yields obtained using these two extraction

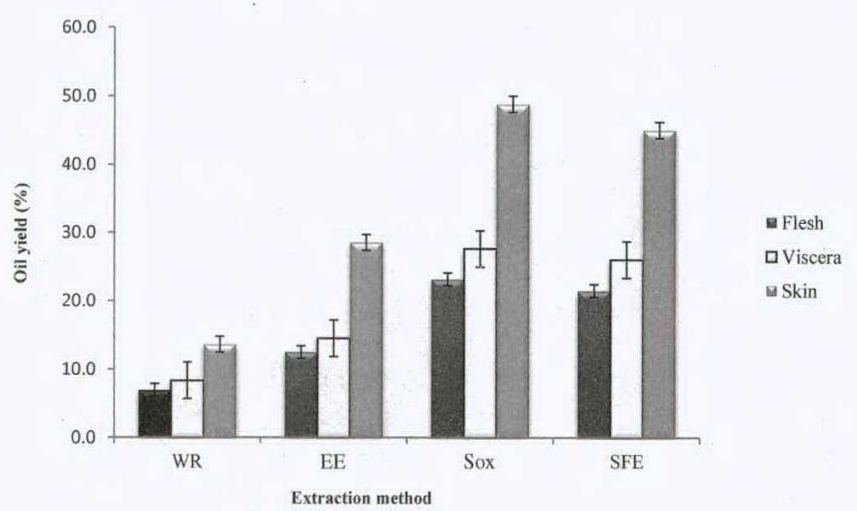

FIGURE 1. Oil yields obtained from different fish tissues using different extraction methods. WR, wet reduction; EE, enzymatic extraction; Sox, Soxhlet; SFE, supercritical fluid extraction.

methods were much lower than that of the SFE method, which might be due to the high moisture content of the raw materials used. Furthermore, when using the enzymatic extraction method, the emulsifying effect of the fish proteins was observed, in which a fraction of the oil remained emulsified in a stable skim fraction, even after centrifugation. This occurrence could be due to the fats being tightly bound to the protein matrix in this fish so that further steps are required to extract the oil. Therefore, these two extraction methods were not as effective in extracting the oil from the short-bodied mackerel compared with the SFE and Soxhlet methods. In the current study, the yield of the oil extracted from different tissues of the short-bodied mackerel using enzymatic extraction ranged from 11 to $28 \%$. Mbatia et al. (24) obtained oil yields of 11.2 and $15.7 \%$ of wet weight from Nile perch and salmon heads, respectively. According to Mbatia et al. (24), during enzymatic extraction, the amount of water added to raw materials that contain lipids has a significant effect on the oil yield. The result of this study was similar to that obtained in previous studies $(25,30)$, Sahena et al. (30) reported a slightly larger amount of fish oil extracted from Indian mackerel using the SFE and Soxhlet methods. However, the trend for the fish oil extracted from the flesh and viscera of the fish was different; in this study, the total fish oil extracted from the viscera was higher than that of the fish flesh using the four extraction methods.

Toxic element reduction. The levels of the toxic elements, namely, mercury, arsenic, cadmium, and lead, in the fish tissues and the extracted fish oils are presented in Table 3. The skin, flesh, and visceral samples of the shortbodied mackerel were contaminated with mercury at $0.28 \pm$ $0.06,0.67 \pm 0.07$, and $0.94 \pm 0.19 \mu \mathrm{g} / \mathrm{g}$ of dry weight, respectively. The fish oil extracted using the SFE method contained considerably lower levels of mercury $(0.09 \pm$ $0.04 \mu \mathrm{g} / \mathrm{g}$ ), which was lower than the accepted limit for human consumption. The recommended maximum accepted limit of the Global Organization for EPA and DHA is $0.1 \mu \mathrm{g}$ / $\mathrm{g}$ for the toxic elements (mercury, arsenic, cadmium, and lead) in fish oil for human consumption (11). The results showed that 85 to $100 \%$ of the mercury content of fish can be avoided by using the SFE method to prepare fish oils. In 


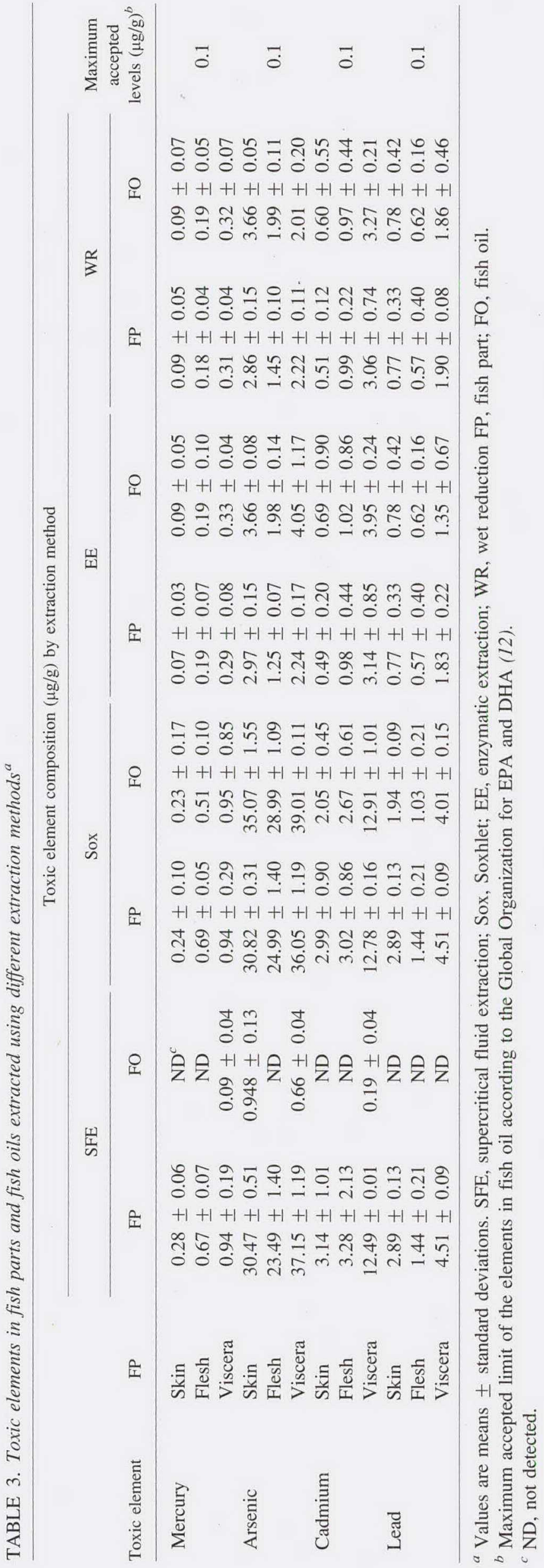

contrast, the non-SFE methods increased the levels of mercury in the fish oils compared with those of the raw materials. This result could be due to the element accumulating in the oil fraction during extraction.

The cadmium content of the fish samples ranged from 2.09 to $12.94 \mu \mathrm{g} / \mathrm{g}$ of dry weight. The cadmium concentration was greater in the oil extracted using the wet reduction and the enzymatic extraction methods, and it exceeded the maximum accepted limit of $0.1 \mu \mathrm{g} / \mathrm{g}$. The cadmium content was reduced in the fish oil extracted using the SFE method; however, it still exceeded the safe limit in some samples (Table 3). The rate of cadmium reduction ranged from 97 to $100 \%$ in fish oil extracted from the skin and flesh using the SFE method. The lead concentration of the fish samples ranged from 1.23 to $4.60 \mu \mathrm{g} / \mathrm{g}$ of dry weight. The concentration was significantly reduced in fish oil extracted using the different methods $(P<0.05)$. However, the concentration was higher than the maximum accepted limit of $0.1 \mu \mathrm{g} / \mathrm{g}$ in fish oils extracted using the non-SFE methods. A $100 \%$ reduction of the lead in fish oil was achieved using supercritical $\mathrm{CO}_{2}$ extraction. The fish samples also contained high levels of arsenic $(37.15 \pm 1.19 \mu \mathrm{g} / \mathrm{g}$ of dry weight), which increased to $39.01 \pm 0.11 \mu \mathrm{g} / \mathrm{g}$ in oil extracted using the non-SFE extraction methods. The fish oil extracted using the SFE method contained a significantly $(P<0.05)$ lower level of arsenic $(0.948 \pm 0.13 \mu \mathrm{g} /$ g). However, this level still exceeds the safe limit recommended for human consumption $(0.1 \mu \mathrm{g} / \mathrm{g})$. The rate of arsenic reduction ranged from 94 to $100 \%$ in fish oil extracted from the skin and flesh using the SFE method.

Previous studies have also reported high levels of arsenic in fish oil supplements. Schmeisser et al. (32) reported arsenic levels of 4.3 to $10.5 \mu \mathrm{g} / \mathrm{g}$ in fish oils. Kołakowska et al. (21) and Lunde (22) reported 6.6 and $3.9 \mu \mathrm{g} / \mathrm{g}$ of arsenic in cod liver oil, respectively. Mercury concentrations of 6 to $12 \mu \mathrm{g} /$ liter have been reported in different brands of fish oil (8). Rubio-Rodríguez et al. (28) reported that negligible amounts of cadmium, mercury, and lead were extracted together with the oil using the SFE method. Nevertheless, fish oil extracted using the SFE method contained 0.05 to $6.70 \mu \mathrm{g} / \mathrm{g}$ arsenic. They claimed a higher arsenic reduction in orange roughy oil compared with salmon oil using the SFE method.

The reduction of toxic elements is highly dependent upon the type of elemental species in the fish tissue that is used. The arsenic detected in fish oils is most likely in the arsenolipids that are coextracted with the oil using the SFE and the other extraction methods. Previous studies $(33,38)$ reported the presence of three arsenolipids in a marine phytoplankton, one of which was a phosphatide and the other two were proposed to be glycolipids. Kohlmeyer et al. (20) suggested the possibility of arsenic binding to cholesterol or fat-soluble vitamins because these compounds are normally present in fish oil.

The greater reduction of the mercury, cadmium, and lead contents of the oil prepared using SFE shows that these elements are most likely attached to polar compounds that are not extracted by SFE. Large amounts of toxic elements 
TABLE 4. Fatty acid compositions of the oils extracted from fish skin using different methods ${ }^{a}$

\begin{tabular}{|c|c|c|c|c|}
\hline \multirow[b]{2}{*}{ Fatty acids } & \multicolumn{4}{|c|}{ Composition of oils $(\mathrm{g} / 100 \mathrm{~g})$ by extraction method } \\
\hline & SFE & Sox & $\mathrm{EE}$ & WR \\
\hline C14:0 & $2.14 \pm 0.19$ & $2.08 \pm 0.14$ & $2.98 \pm 0.08$ & $3.64 \pm 0.13$ \\
\hline C16:0 & $8.50 \pm 0.08$ & $8.88 \pm 0.17$ & $9.01 \pm 0.10$ & $10.40 \pm 0.08$ \\
\hline C17:0 & $2.11 \pm 0.03$ & $2.29 \pm 0.11$ & $1.99 \pm 0.07$ & $2.36 \pm 0.03$ \\
\hline C18:0 & $1.99 \pm 0.06$ & $2.11 \pm 0.08$ & $2.73 \pm 0.04$ & $2.74 \pm 0.01$ \\
\hline $\mathrm{C} 20: 0$ & $1.01 \pm 0.20$ & $1.54 \pm 0.09$ & $1.48 \pm 0.03$ & $1.94 \pm 0.07$ \\
\hline$\sum$ saturated fatty acids & $15.75 \pm 0.56$ & $16.90 \pm 0.59$ & $18.19 \pm 0.32$ & $21.08 \pm 0.32$ \\
\hline $\mathrm{C} 16: 1 \omega 7$ & $0.18 \pm 0.02$ & $0.19 \pm 0.05$ & $0.15 \pm 0.03$ & $0.14 \pm 0.09$ \\
\hline C18:1 & $0.94 \pm 0.10$ & $1.17 \pm 0.03$ & $1.12 \pm 0.08$ & $1.00 \pm 0.01$ \\
\hline $\mathrm{C} 18: 1 \omega 9$ & $3.11 \pm 0.09$ & $3.76 \pm 0.14$ & $2.44 \pm 0.12$ & $1.06 \pm 0.05$ \\
\hline $\mathrm{C} 18: 1 \omega 7$ & $1.02 \pm 0.01$ & $1.28 \pm 0.02$ & $1.01 \pm 0.04$ & $0.93 \pm 0.03$ \\
\hline $\mathrm{C} 20: 1 \omega 9$ & $0.09 \pm 0.01$ & $0.14 \pm 0.01$ & $0.12 \pm 0.03$ & $0.12 \pm 0.02$ \\
\hline $\mathrm{C} 22: 1$ & $3.01 \pm 0.09$ & $3.44 \pm 0.06$ & $3.18 \pm 0.11$ & $2.44 \pm 0.09$ \\
\hline$\sum$ monounsaturated fatty acids & $8.35 \pm 0.32$ & $9.98 \pm 0.31$ & $8.02 \pm 0.41$ & $5.69 \pm 0.29$ \\
\hline $\mathrm{C} 16: 3 \omega 3$ & $7.17 \pm 0.13$ & $6.88 \pm 0.16$ & $5.15 \pm 0.07$ & $2.11 \pm 0.15$ \\
\hline $\mathrm{C} 18: 3 \omega 3$ & $0.69 \pm 0.02$ & $0.55 \pm 0.05$ & $0.49 \pm 0.02$ & $\mathrm{ND}^{b}$ \\
\hline $\mathrm{C} 18: 4 \omega 3$ & $3.91 \pm 0.09$ & $3.57 \pm 0.09$ & $2.44 \pm 0.09$ & $0.93 \pm 0.03$ \\
\hline $\mathrm{C} 20: 3 \omega 3$ & $1.69 \pm 0.03$ & $1.15 \pm 0.09$ & $0.91 \pm 0.01$ & $0.31 \pm 0.07$ \\
\hline $\mathrm{C} 20: 4 \omega 3$ & $0.87 \pm 0.01$ & $0.81 \pm 0.08$ & $0.45 \pm 0.01$ & ND \\
\hline $\mathrm{C} 20: 5 \omega 3$ (EPA) & $12.09 \pm 0.12$ & $11.81 \pm 0.09$ & $5.19 \pm 0.05$ & $0.93 \pm 0.03$ \\
\hline $\mathrm{C} 22: 5 \omega 3$ (DPA) & $4.13 \pm 0.05$ & $3.80 \pm 0.06$ & $1.77 \pm 0.02$ & ND \\
\hline 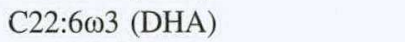 & $17.19 \pm 0.10$ & $16.89 \pm 0.07$ & $6.93 \pm 0.09$ & $0.96 \pm 0.06$ \\
\hline$\sum \omega 3$-PUFA & $47.74 \pm 0.55$ & $45.46 \pm 0.69$ & $23.33 \pm 0.36$ & $5.24 \pm 0.34$ \\
\hline $\mathrm{C} 18: 3 \omega 6$ & $3.48 \pm 0.03$ & $3.19 \pm 0.09$ & $1.44 \pm 0.10$ & ND \\
\hline $\mathrm{C} 18: 2 \omega 6$ & $11.93 \pm 0.05$ & $11.13 \pm 0.01$ & $9.08 \pm 0.05$ & $2.48 \pm 0.08$ \\
\hline $\mathrm{C} 20: 4 \omega 6$ & $2.46 \pm 0.07$ & $2.90 \pm 0.13$ & $1.90 \pm 0.01$ & ND \\
\hline $\mathrm{C} 22: 5 \omega 6$ & $4.30 \pm 0.04$ & $4.33 \pm 0.01$ & $2.05 \pm 0.07$ & $0.18 \pm 0.04$ \\
\hline$\sum \omega 6$-PUFA & $22.17 \pm 0.19$ & $21.55 \pm 0.24$ & $14.47 \pm 0.23$ & $2.66 \pm 0.12$ \\
\hline$\sum$ PUFAs & $69.91 \pm 0.74$ & $67.01 \pm 0.93$ & $37.80 \pm 0.59$ & $7.90 \pm 0.46$ \\
\hline$\omega 6 / \omega 3$ & 0.46 & 0.47 & 0.62 & 0.50 \\
\hline
\end{tabular}

${ }^{a}$ Values are means \pm standard deviations. SFE, supercritical fluid extraction; Sox, Soxhlet; EE, enzymatic extraction; WR, wet reduction; DPA, docosapentaenoic acid.

${ }^{b} \mathrm{ND}$, not detected.

were extracted with the oil using the non-SFE methods, such as wet reduction and enzymatic extraction. This result also indicates those elements being bound to fatty compounds rather than to proteins. The free fatty acids and triglycerides in the oil phase are the most likely organic compounds to which metals would bind. Tavakoli and Yoshida (35) proposed that the free fatty acids and triglycerides in squid oil perform metal chelating reactions. They suggested that free fatty acids have a high affinity for metal ions. According to their study, fatty acids and triglycerides are able to bind divalent heavy metal ions. At high temperatures, the double bonds of the triglyceride molecules are broken, which lead to their saturation (31). Under these conditions, the unsaturated fatty acids decompose and easily react with metal ions. Extracting fish oil at a high temperature using the wet reduction method caused thermal decomposition and, consequently, lower levels of PUFAs in the oil. The higher levels of toxic elements in the fish oils extracted at $95^{\circ} \mathrm{C}$ using the wet reduction method can also be explained by the higher levels of free fatty acids in those oils compared with the oils extracted using the other three methods.
Fatty acid compositions of the extracted fish oils. Tables 4 through 6 show the fatty acid compositions of the oils extracted from the skin, flesh, and viscera of the shortbodied mackerel using the SFE, Soxhlet, enzymatic extraction, and wet reduction methods. The fatty acid contents varied according to the extraction method employed. The highest PUFA content was observed in oil extracted using the SFE method, followed by that extracted using the Soxhlet method. The amounts of PUFAs extracted from the skin, flesh, and viscera using the SFE method ranged from 69.17 to 70.65 , from 63.69 to 65.25 , and from 59.06 to $61.97 \mathrm{~g} / 100 \mathrm{~g}$, respectively. The largest amounts of omega- 3 fatty acids, mainly EPA and DHA, were extracted from fish skin and flesh using the SFE method. The EPA contents of the skin, flesh, and viscera were $12.09 \pm 0.12$, $11.22 \pm 0.04$, and $10.53 \pm 0.01 \mathrm{~g} / 100 \mathrm{~g}$, respectively. The amounts of DHA in the skin, flesh, and viscera were 17.19 $\pm 0.10,16.70 \pm 0.09$, and $15.23 \pm 0.05 \mathrm{~g} / 100 \mathrm{~g}$, respectively.

Fish oil can be produced using several methods, some of which necessitate heat treatment, which may affect the quality of the PUFAs. The results showed that fish oil 
TABLE 5. Fatty acid compositions of the oils extracted from fish flesh using different methods ${ }^{a}$

\begin{tabular}{|c|c|c|c|c|}
\hline \multirow[b]{2}{*}{ Fatty acids } & \multicolumn{4}{|c|}{ Composition of oils ( $\mathrm{g} / 100 \mathrm{~g}$ ) by extraction method } \\
\hline & SFE & Sox & $\mathrm{EE}$ & WR \\
\hline $\mathrm{C} 14: 0$ & $2.50 \pm 0.04$ & $2.44 \pm 0.08$ & $3.09 \pm 0.03$ & $4.66 \pm 0.10$ \\
\hline $\mathrm{C} 16: 0$ & $8.91 \pm 0.02$ & $8.96 \pm 0.11$ & $9.04 \pm 0.03$ & $9.83 \pm 0.07$ \\
\hline $\mathrm{C} 17: 0$ & $2.29 \pm 0.09$ & $2.57 \pm 0.05$ & $2.21 \pm 0.05$ & $3.18 \pm 0.07$ \\
\hline C18:0 & $1.86 \pm 0.01$ & $1.89 \pm 0.03$ & $2.96 \pm 0.09$ & $4.16 \pm 0.09$ \\
\hline $\mathrm{C} 20: 0$ & $0.97 \pm 0.09$ & $1.30 \pm 0.03$ & $1.08 \pm 0.11$ & $1.75 \pm 0.03$ \\
\hline$\sum$ saturated fatty acids & $16.53 \pm 0.25$ & $17.16 \pm 0.30$ & $18.38 \pm 0.31$ & $23.13 \pm 0.36$ \\
\hline $\mathrm{C} 16: 1 \omega 7$ & $0.25 \pm 0.08$ & $0.32 \pm 0.02$ & $0.22 \pm 0.08$ & $0.12 \pm 0.10$ \\
\hline C18:1 & $0.99 \pm 0.02$ & $1.02 \pm 0.02$ & $1.45 \pm 0.07$ & $1.20 \pm 0.08$ \\
\hline $\mathrm{C} 18: 1 \omega 9$ & $3.18 \pm 0.09$ & $3.90 \pm 0.05$ & $2.86 \pm 0.10$ & $1.01 \pm 0.02$ \\
\hline $\mathrm{C} 18: 1 \omega 7$ & $1.70 \pm 0.09$ & $1.99 \pm 0.11$ & $0.95 \pm 0.07$ & $1.17 \pm 0.05$ \\
\hline $\mathrm{C} 20: 1 \omega 9$ & $0.24 \pm 0.05$ & $0.35 \pm 0.01$ & $0.17 \pm 0.00$ & $0.14 \pm 0.05$ \\
\hline $\mathrm{C} 22: 1$ & $3.19 \pm 0.11$ & $3.29 \pm 0.08$ & $3.10 \pm 0.02$ & $2.65 \pm 0.07$ \\
\hline$\sum$ monounsaturated fatty acids & $9.55 \pm 0.44$ & $10.87 \pm 0.29$ & $8.75 \pm 0.34$ & $6.29 \pm 0.37$ \\
\hline $\mathrm{C} 16: 3 \omega 3$ & $7.11 \pm 0.04$ & $6.62 \pm 0.04$ & $4.75 \pm 0.08$ & $1.83 \pm 0.02$ \\
\hline $\mathrm{C} 18: 3 \omega 3$ & $0.55 \pm 0.07$ & $0.60 \pm 0.01$ & $0.53 \pm 0.01$ & $\mathrm{ND}^{b}$ \\
\hline $\mathrm{C} 18: 4 \omega 3$ & $3.77 \pm 0.01$ & $3.22 \pm 0.02$ & $2.10 \pm 0.02$ & $0.87 \pm 0.02$ \\
\hline $\mathrm{C} 20: 3 \omega 3$ & $1.68 \pm 0.01$ & $1.09 \pm 0.11$ & $0.93 \pm 0.05$ & $0.43 \pm 0.05$ \\
\hline $\mathrm{C} 20: 4 \omega 3$ & $0.91 \pm 0.03$ & $0.87 \pm 0.05$ & $0.50 \pm 0.07$ & ND \\
\hline C20:5 13 (EPA) & $11.22 \pm 0.04$ & $11.11 \pm 0.02$ & $5.00 \pm 0.10$ & $0.97 \pm 0.01$ \\
\hline $\mathrm{C} 22: 5 \omega 3$ (DPA) & $4.01 \pm 0.02$ & $3.85 \pm 0.06$ & $1.14 \pm 0.09$ & ND \\
\hline $\mathrm{C} 22: 6 \omega 3$ (DHA) & $16.70 \pm 0.09$ & $16.44 \pm 0.01$ & $6.17 \pm 0.02$ & $0.79 \pm 0.10$ \\
\hline$\sum \omega 3$-PUFA & $45.95 \pm 0.55$ & $43.80 \pm 0.32$ & $21.12 \pm 0.44$ & $4.89 \pm 0.20$ \\
\hline $\mathrm{C} 18: 3 \omega 6$ & $3.08 \pm 0.11$ & $3.01 \pm 0.01$ & $1.00 \pm 0.02$ & ND \\
\hline $\mathrm{C} 18: 2 \omega 6$ & $10.24 \pm 0.01$ & $10.66 \pm 0.02$ & $8.42 \pm 0.05$ & $2.21 \pm 0.02$ \\
\hline $\mathrm{C} 20: 4 \omega 6$ & $2.09 \pm 0.02$ & $2.53 \pm 0.02$ & $1.23 \pm 0.03$ & ND \\
\hline $\mathrm{C} 22: 5 \omega 6$ & $4.11 \pm 0.09$ & $3.57 \pm 0.08$ & $1.70 \pm 0.09$ & ND \\
\hline$\sum \omega 6-P U F A$ & $18.52 \pm 0.23$ & $19.77 \pm 0.13$ & $14.47 \pm 0.23$ & $2.21 \pm 0.02$ \\
\hline$\sum$ PUFAs & $64.47 \pm 0.78$ & $63.57 \pm 0.45$ & $35.59 \pm 0.67$ & $7.00 \pm 0.22$ \\
\hline$\omega 6 / \omega 3$ & 0.40 & 0.45 & 0.68 & 0.45 \\
\hline
\end{tabular}

${ }^{a}$ Values are means \pm standard deviations. SFE, supercritical fluid extraction; Sox, Soxhlet; EE, enzymatic extraction; WR, wet reduction; DPA, docosapentaenoic acid.

${ }^{b} \mathrm{ND}$, not detected.

extracted using the wet reduction method contained the lowest levels of PUFAs and omega- 3 fatty acids. The total PUFA content of the oils extracted from fish skin, flesh, and viscera using the wet reduction method were $7.90 \pm 0.46$, $7.00 \pm 0.22$, and $4.76 \pm 0.17 \mathrm{~g} / 100 \mathrm{~g}$, respectively. Due to emulsion formation during extraction, the amounts of PUFAs and other fatty acids obtained using enzymatic extraction were lower than those obtained using the SFE and Soxhlet methods. The total PUFA contents of fish skin, flesh, and viscera were $37.80 \pm 0.59,35.59 \pm 0.67$, and $29.62 \pm 0.41 \mathrm{~g} / 100 \mathrm{~g}$, respectively. However, the amounts of EPA and DHA recovered were significantly higher $(P<$ $0.05)$ than those recovered using the wet extraction method.

SFE of oil is an efficient method because it involves the application of mild temperatures that prevent the oxidation of the PUFAs. In this study, the oil extracted from fish skin using the SFE method had the highest concentration of total omega- 3 fatty acids $(47.74 \pm 0.55 \mathrm{~g} / 100 \mathrm{~g}$ oil). The contents of omega- 6 fatty acids in the oils extracted from fish flesh and viscera using the Soxhlet method were higher than those obtained using the SFE method. However, the difference was not significant $(P<0.05)$. Short-bodied mackerel have lower contents of saturated fatty acids and monounsaturated fatty acids than do Indian mackerel, as reported by Sahena et al. (30) and Osman et al. (25). Whereas the content of omega-3 PUFAs was higher than that reported for Indian mackerel, the omega-6 PUFAs content was in the same range.

Irrespective of the method of extraction, the omega-6/ omega- 3 ratio was in the acceptable range in all of the oil samples. The omega-6/omega-3 ratio is a good index for comparing the nutritional values of fish oils from different fish species. The optimal balance of these fatty acids in the human body is 1:1 (34). According to the World Health Organization recommendation, this ratio should not exceed 5.0 in the total human diet (37).

The results of this study showed that fish oils produced using the conventional methods, such as wet reduction, enzymatic extraction, and Soxhlet extraction contain levels of toxic elements that are greater than those of the corresponding fish tissues. Therefore, a subsequent refining process is needed for these oils to meet the quality standards required for human consumption. Due to their distinctive extraction mechanisms, various extraction techniques achieved different rates of reduction of the toxic elements. 
TABLE 6. Fatty acid compositions of oils extracted from fish viscera using SFE and Soxhlet methods ${ }^{a}$

\begin{tabular}{|c|c|c|}
\hline \multirow[b]{2}{*}{ Fatty acids } & \multicolumn{2}{|c|}{$\begin{array}{l}\text { Composition of oils }(\mathrm{g} / 100 \mathrm{~g}) \text { by } \\
\text { extraction method }\end{array}$} \\
\hline & SFE & Soxhlet \\
\hline $\mathrm{C} 14: 0$ & $3.39 \pm 0.11$ & $3.51 \pm 0.05$ \\
\hline C16:0 & $9.41 \pm 0.04$ & $9.51 \pm 0.02$ \\
\hline $\mathrm{C} 17: 0$ & $2.82 \pm 0.01$ & $2.90 \pm 0.06$ \\
\hline $\mathrm{C} 18: 0$ & $2.34 \pm 0.13$ & $2.65 \pm 0.08$ \\
\hline $\mathrm{C} 20: 0$ & $2.68 \pm 0.06$ & $2.59 \pm 0.08$ \\
\hline$\sum$ saturated fatty acids & $20.64 \pm 0.35$ & $21.16 \pm 0.29$ \\
\hline $\mathrm{C} 16: 1 \omega 7$ & $0.53 \pm 0.09$ & $0.63 \pm 0.10$ \\
\hline $\mathrm{C} 18: 1$ & $1.17 \pm 0.09$ & $1.33 \pm 0.01$ \\
\hline $\mathrm{C} 18: 1 \omega 9$ & $3.52 \pm 0.02$ & $3.99 \pm 0.01$ \\
\hline $\mathrm{C} 18: 1 \omega 7$ & $2.01 \pm 0.06$ & $2.25 \pm 0.05$ \\
\hline $\mathrm{C} 20: 1 \omega 9$ & $0.52 \pm 0.01$ & $0.46 \pm 0.04$ \\
\hline $\mathrm{C} 22: 1$ & $3.22 \pm 0.01$ & $3.73 \pm 0.04$ \\
\hline$\sum$ monounsaturated fatty acids & $10.97 \pm 0.28$ & $12.39 \pm 0.25$ \\
\hline 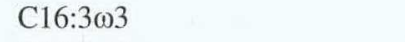 & $6.69 \pm 0.04$ & $6.41 \pm 0.02$ \\
\hline $\mathrm{C} 18: 3 \omega 3$ & $0.59 \pm 0.08$ & $0.42 \pm 0.09$ \\
\hline $\mathrm{C} 18: 4 \omega 3$ & $3.56 \pm 0.09$ & $3.10 \pm 0.10$ \\
\hline $\mathrm{C} 20: 3 \omega 3$ & $1.48 \pm 0.00$ & $1.11 \pm 0.02$ \\
\hline $\mathrm{C} 20: 4 \omega 3$ & $0.79 \pm 0.01$ & $0.53 \pm 0.02$ \\
\hline C20:5 03 (EPA) & $10.59 \pm 0.01$ & $10.19 \pm 0.08$ \\
\hline $\mathrm{C} 22: 5 \omega 3$ (DPA) & $3.80 \pm 0.04$ & $3.88 \pm 0.12$ \\
\hline $\mathrm{C} 22: 6 \omega 3$ (DHA) & $15.40 \pm 0.09$ & $15.06 \pm 0.04$ \\
\hline$\sum \omega 3$-PUFA & $42.90 \pm 0.36$ & $40.70 \pm 0.49$ \\
\hline $\mathrm{C} 18: 3 \omega 6$ & $2.81 \pm 0.05$ & $2.59 \pm 0.09$ \\
\hline $\mathrm{C} 18: 2 \omega 6$ & $10.10 \pm 0.06$ & $10.70 \pm 0.08$ \\
\hline 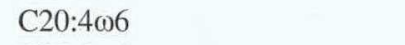 & $1.66 \pm 0.10$ & $2.03 \pm 0.04$ \\
\hline $\mathrm{C} 22: 5 \omega 6$ & $3.98 \pm 0.09$ & $3.13 \pm 0.05$ \\
\hline$\sum \omega 6$-PUFA & $18.55 \pm 0.30$ & $18.45 \pm 0.26$ \\
\hline$\sum$ PUFAs & $61.45 \pm 0.66$ & $59.15 \pm 0.75$ \\
\hline$\omega 6 / \omega 3$ & 0.43 & 0.45 \\
\hline
\end{tabular}

${ }^{a}$ Values are means \pm standard deviations. SFE, supercritical fluid extraction; Sox, Soxhlet; DPA, docosapentaenoic acid.

The reduction of toxic elements using the SFE method was significantly more efficient than that of the other methods due to the high selectivity of supercritical $\mathrm{CO}_{2}$ for nonpolar compounds. Most of the toxic element residues were eliminated from fish oil by using the supercritical technique. The fish oil extracted from the skin and flesh using the SFE method was entirely free of mercury contamination. Among the toxic elements, arsenic was detected in high levels in the fish oils, which could be due to the lipid solubility of some arsenic species. Therefore, to more effectively reduce the arsenic in fish oil, we recommended optimizing the SFE conditions. Overall, this study showed that compared with other oil extraction methods, SFE is an efficient method because it extracts oils with high quality and low levels of impurities. This study also showed that the skin and viscera of the short-bodied mackerel are valuable raw materials for obtaining high-quality fish oil.

\section{ACKNOWLEDGMENT}

We thank the Ministry of Science, Technology and Innovation of Malaysia for financial support of this research under EScience Fund Project (grant 04-01-04-SF1435).

\section{REFERENCES}

1. Agusa, T., T. Kunito, A. Sudaryanto, I. Monirith, S. K. Atireklap, and H. Iwata. 2007. Exposure assessment for trace elements from consumption of marine fish in Southeast Asia. Environ. Pollut. 145:766-777.

2. Allen, K. G. D., and M. A. Harris. 2001. The role of n-3 fatty acids in gestation and parturition. Exp. Biol. Med. 226:498-506.

3. AOAC International. 2000. Loss of drying (moisture) at $95-100^{\circ} \mathrm{C}$ for feeds/dry matter on oven drying at $95-100^{\circ} \mathrm{C}$ for feeds, p. 30-59. W. Horwitz (ed.), Official methods of analysis of AOAC International, 17th ed. AOAC International, Gaithersburg, MD.

4. Bourgoin, M. L., I. Quiroga, J. Chincheros, and P. Courau. 2000. Mercury distribution in waters and fishes of the upper Madeira rivers and mercury exposure in riparian Amazonian populations. Sci. Total Environ. 260:73-86.

5. Connor, W. E. 2000. Importance of n-3 fatty acids in health and disease. Am. J. Clin. Nutr. 71:171S-175S.

6. de Lorgeril, M., P. Salen, J. L. Martin, I. Monjaud, J. Delaye, and N. Mamelle. 1999. Mediterranean diet, traditional risk factors, and the rate of cardiovascular complications after myocardial infarction: final report of the Lyon Diet Heart Study. Circulation 99:779-785.

7. Faisal, M., Y. Atsuta, H. Daimon, and K. Fujie. 2008. Recovery of precious metals from spent automobile catalytic converters using supercritical carbon dioxide. Asia-Pac. J. Chem. Eng. 3:364-367.

8. Foran, S. E., J. G. Flood, and K. B. Lewandrowski. 2003. Measurement of mercury levels in concentrated over-the-counter fish oil preparations: is fish oil healthier than fish?. Arch. Pathol. Lab. Med. 127:1603-1605.

9. Freeman, M. P. 2000. Omega-3 fatty acids in psychiatry: a review. Ann. Clin. Psychiatry 12:159-165.

10. Gelmez, N., N. Kincal, and M. Yener. 2009. Optimization of supercritical carbon dioxide extraction of antioxidants from roasted wheat germ based on yield, total phenolic and tocopherol contents, and antioxidant activities of the extracts. J. Supercrit. Fluids 48:217224.

11. Global Organization for EPA and DHA Omega-3. 2012. Voluntary monograph 4. Available at: http://www.goedomega3.com. Accessed 24 March 2013.

12. Gruppo Italiano per lo Studio della Sopravvivenza nell'Infarto miocardico. 1999. Dietary supplementation with n-3 polyunsaturated fatty acids and vitamin $\mathrm{E}$ after myocardial infarction: results of the GISSI-Prevenzione trial. Lancet 354:447-455.

13. Guallar, E., I. Sanz-Gallardo, P. V. Veer, P. Bode, A. Aro, and J. Gómez-Aracena. 2002. Mercury, fish oils, and myocardial infarction. N. Engl. J. Med. 347:1747.

14. Hajeb, P., S. Jinap, A. B. Fatimah, and B., Jamilah, 2010. Methylmercury in marine fish from malaysian waters and its relationship to total mercury content. Int. J. Environ. Anal. Chem. 90:812-820.

15. Hajeb, P., S. Jinap, A. Ismail, A. B. Fatimah, B., Jamilah, and M. Abdul Rahim. 2009. Assessment of mercury level in commonly consumed marine fishes in Malaysia. Food Control 20:79-84.

16. Kataeva, M., N. Panichev, and A. E. Wyk. 2009. Monitoring mercury in two South African herbaria. Sci. Total Environ. 407:1211-1217.

17. Kawashima, A., S. Watanabe, R. Iwakiri, and K. Honda. 2009. Removal of dioxins and dioxin-like PCBs from fish oil by countercurrent supercritical $\mathrm{CO}_{2}$ extraction and activated carbon treatment. Chemosphere 75:788-794.

18. Khoddami, A., A. Ariffin, J. Bakar, and H. Ghazali. 2012. Quality and fatty acid profile of the oil extracted from fish waste (head, intestine and liver) (Euthynnus affinis). Afr. J. Biotechnol. 11:16831689.

19. Koh, M., J. Yoo, M. Ju, B. Joo, K. Park, and H. Kim. 2008. Surface decontamination of radioactive metal wastes using acid-in-supercritical $\mathrm{CO}_{2}$ emulsions. Ind. Eng. Chem. Res. 47:278-283.

20. Kohlmeyer, U., S. Jakubik, J. Kuballa, and E. Jantzen. 2005. Determination of arsenic species in fish oil after acid digestion. Microchim. Acta 151:249-255.

21. Kołakowska, A., K. Stypkto, Z. Domiszewski, G. Bienkiewics, A. Perkowska, and A. Witczak. 2002. Canned cod liver as a source of n- 
3 polyunsaturated fatty acids, with a reference to contamination. Food 46:40-45.

22. Lunde, G. 1968. Analysis of arsenic in marine oils by neutron activation, evidence of arseno organic compounds. J. Am. Oil Chem. Soc. 45:331-332.

23. Maes, J., B. De Meulenaer, P. Van Heerswynghels, W. De Greyt, G. Eppe, and E. De Pauw. 2005. Removal of dioxins and PCB from fish oil by activated carbon and its influence on the nutritional quality of the oil. J. Am. Oil Chem. Soc. 82:539-597.

24. Mbatia, B., D. Adlercreutz, P. Adlercreutz, A. Mahadhy, F. Mulaa, and B. Mattiasson. 2010. Enzymatic oil extraction and positional analysis of $\mathrm{n}-3$ fatty acids in Nile perch and salmon heads. Process Biochem. 45:815-819.

25. Osman, F., I. Jaswir, H. Khaza'ai, and R. Hashim. 2007. Fatty acid profiles of fin fish in Langkawi Island, Malaysia. J. Oleo Sci. 56:107113.

26. Passos, C. P., S. Yilmaz, C. M. Silva, and M. A. Coimbra, 2009. Enhancement of grape seed oil extraction using a cell wall degrading enzyme cocktail. Food Chem. 115:48-53.

27. Riediger, N. D., R. A. Othman, M. Suh, and M. H. Moghadasian. 2009. A systemic review of the roles of $n-3$ fatty acids in health and disease. J. Am. Diet Assoc. 109:668-679.

28. Rubio-Rodríguez, N., S. M. de Diego, S. Beltrán, I. Jaime, M. T. Sanz, and J. Rovira. 2012. Supercritical fluid extraction of fish oil from fish by-products: a comparison with other extraction methods. $J$. Food Eng. 109:238-248.

29. Sahena, F., I. S. M. Zaidul, S. Jinap, M. H. A. Jahurul, A. Khatib, and N. A. N. Norulaini. 2010. Extraction of fish oil from the skin of Indian mackerel using supercritical fluids. J. Food Eng. 99:63-69.

30. Sahena, F., I. S. M. Zaidul, S. Jinap, A. M. Yazid, A. Khatib, and N. A. N. Norulaini. 2010. Fatty acid compositions of fish oil extracted from different parts of Indian mackerel (Rastrelliger kanagurta) using various techniques of supercritical $\mathrm{CO} 2$ extraction. Food Chem. 120: 879-885.

31. Santos, J. C. O., I. M. G. dos Santos, A. G. de Souza, S. Prasad, and A. V. dos Santos. 2002. Thermal stability and kinetic study on thermal decomposition of commercial edible oils by thermogravimetry. J. Food Sci. 67:1393-1398.

32. Schmeisser, E., W. Goessler, N. Kienzl, and K. A. Francesconi. 2005. Direct measurement of lipid-soluble arsenic species in biological samples with HPLC-ICPMS. Analyst 130:948-955.

33. Selea, V., J. J. Sloth, A. K. Lundebye, E. H. Larsen, M. H. G. Berntssena, and H. Amlund, 2012. Arsenolipids in marine oils and fats: a review of occurrence, chemistry and future research needs. Food Chem. 133:618-630.

34. Simopoulos, A. P. 1989. Summary of NATO advanced research workshop on dietary omega 3 and omega 6 fatty acids: biological effects and nutritional essentiality. J. Nutr. 199:512-528.

35. Tavakoli, O., and H. Yoshida. 2005. Effective recovery of harmful metal ions from squid wastes using subcritical and supercritical water treatments. Environ. Sci. Technol. 39:2357-2363.

36. von Schacky, C., P. Angerer, W. Kothny, K. Theisen, and H. Mudra. 1999. The effect of dietary omega-3 fatty acids on coronary atherosclerosis: a randomized, doubleblind, placebo-controlled trial. Ann. Intern. Med. 130:554-562.

37. Vujkovic, G., D. Karlovic, I. Vujkovic, I. Vorosbaranyi, and B. Jovanovic. 1999. Comparison of muscle tissue lipids of silver carp and bighead carp. J. Am. Oil Chem. Soc. 76:475-480.

38. Wrench, J. J., and R. F. Addison. 1981. Reduction, methylation, and incorporation of arsenic into lipids by the marine phytoplankton Dunaliella tertiolecta. Can. J. Fish. Aquat. Sci. 38:518523. 
Copyright of Journal of Food Protection is the property of Allen Press Publishing Services Inc. and its content may not be copied or emailed to multiple sites or posted to a listserv without the copyright holder's express written permission. However, users may print, download, or email articles for individual use. 